\title{
Augmented Reality Design of Indonesia Fruit Recognition
}

\author{
Dewi Agushinta R. ${ }^{1}$, Ihsan Jatnika ${ }^{2}$, Henny Medyawati ${ }^{3}$, Hustinawaty ${ }^{4}$ \\ ${ }^{1,3}$ Department of Information System, Gunadarma University, Indonesia \\ ${ }^{2,4}$ Department of Informatics, Gunadarma University, Indonesia
}

\begin{tabular}{l}
\hline \hline Article Info \\
\hline Article history: \\
Received Sep 30, 2017 \\
Revised May 3, 2018 \\
Accepted Jun 2, 2018
\end{tabular}

Keyword:

Android

Augmented reality

Design

FruitGarden

\begin{abstract}
Augmented Reality (AR) is one of the popular technologies nowadays. Along with the technological advances, Augmented Reality is an effort to combine the real world and virtual worlds created through computers so that the boundary between the two becomes very thin because Augmented Reality allows users to interact in real-time with the system. Augmented Reality can be applied in various fields according to the needs of each user. One application is on Android-based mobile hardware applications. This research developed the Augmented Reality battle with some of the features more interactive, interesting and clearer information to facilitate the user in its operation. This Augmented Reality is applied to the Android mobile device with the name of FruitGarden. This paper presented of designing Augmented Reality for recognizing the fruit of Indonesia archipelago which will give a different view of performing the fruit image and information.
\end{abstract}

Copyright $@ 2018$ Institute of Advanced Engineering and Science. All rights reserved.

\section{Corresponding Author:}

Dewi Agushinta R,

Department of Information System, Gunadarma University,

Jl. Margonda Raya No. 100 Pondok Cina, Depok 16424, West Java, Indonesia.

Email: dewiar@staff.gunadarma.ac.id

\section{INTRODUCTION}

The development of computer technology and the support of information technology based on mobile much help in solving information and communication problem. Everyone is very easy to access information without being attached to the place because of the easy access to Internet networks and mobilebased information-based devices. In the early development of mobile devices, especially mobile phones, each vendor makes their own platform, so the application is made only for a product. This is not profitable for the development of the application itself because the existing applications are very dependent on the brand of mobile phones. A platform that is currently in use by many application developers is Android. They choose this operating system because it is open source.

The developers can use it for free by customizing the applications that will be in use. Augmented Reality (AR) is a technology that combines three-dimensional virtual objects into a real three-dimensional environment and displays them in real time. Unlike virtual reality that completely supersedes reality, a reality is added simply to add or complement reality. Improved reality can be applied to all senses, including hearing, touch, and smell. A navigation system with an AR application that uses a camera and GPS is introduced. The information around the user will be reflected in real-time. Users can find the building they are looking for or get what they want around. The technology made is divided into three bases, sensors, vision and hybrid tracing technology [1]. An AR prototype has been proposed to suppress oil leaks. Oil leakage sensor data makes exploration and data visualization difficult to manage. Automatic AR that can scientifically visualize, make identification, localization, and visualization of leakage data can be selected and managed with the development of prototype [2]. However, the AR technology with the subject of fruit are still rare.

Augmented Reality can also be used as a medium of recognition of an object such as the introduction of fruit types in the form of information by using a mobile Android device. In this paper, 
Augmented Reality will use a different recognition method to visualize the image of fruit as an object. A fruit recognition technique is developed based on color, shape attributes and size-based. The method classifies and recognizes fruit images based on obtained features values by using nearest neighbor classification [3]. A viewpoint invariant solution for intra-class recognition of fruits by combining color and texture features using a Neural Network (NN) classifier is experimented [4]. Proposed of image analysis algorithms estimation models performed accurately using canopy and fruit features using BPNN [5]. However, these methods used two-dimensional image data of fruits.

A different method to recognize the fruits has created. AR creates a modern environment by combining real and virtual environments' interactivity so the users feel that the environment created is real. Three-dimension image data of fruit can be emerged, exposing some information on the fruit type directly by the support of multiple sensors set on AR mobile devices [6]. This paper presents the design of making this FruitGarden AR application, but not the implementation yet. This FruitGarden application will give a real environment information. The paper will consist of some parts, an introduction, the method, the UML design, with a discussion and the conclusion.

\section{METHOD}

The research method used for designing the Augmented Reality is divided into several stages, shown in Figure 1. In the planning phase, identification of problems and information related to research is performed. Supporting theories are collected from many resources. Furthermore, in the analysis phase formulated problem-solving based on supporting theory that has been collected in the form of an overview of the workings of the application program created. At the design stage of the application program is designed in accordance with the problem solving that has been determined. The design conducted by creating a Unified Modeling Language (UML) modeling as well as designing the interface [7].

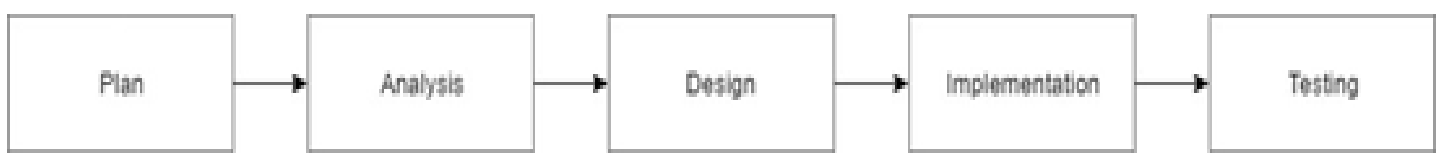

Figure 1. The method

In designing this Augmented Reality application program, we need to consider and analyze hardware and software requirement that will be used for the program can run as expected. The process of developing this application program requires hardware and software as media and tools used. It starts from the model design until the completed program as well when the program is implemented into the real environment.

There is some hardware required for the FruitGarden application program starts from the manufacture, storage until the program is used in the actual condition. First is a computer that is used for designing, writing programs, and testing the program. Next is a database server that serves as database storage containing fruit data and other information will be used for the program.

In addition, this program requires a mobile device that has a minimal Android camera sensor. Almost all mobile devices with the Android operating system already have the camera. This tool serves as a medium to install and run programs that will be used by the user to get information on the fruits. Table 1 is a list of hardware used to create and run programs.

It also requires software for programming and implementing it besides the hardware. In addition to the operating system that became the basic software, the design of the program for the developers of the Android operating system requires other software. The software includes JDK, Eclipse, ADT Plugin, Android SDK, Map API, Wikitude API, and MySQL to process database server. Table 2 is a list of software used to create and run the program.At this stage, a model will be designed in Unified Modeling Language (UML), and the FruitGarden application interface as well. 
Table 1. Hardware Requirement

\begin{tabular}{cll}
\hline Hardware & \multicolumn{1}{c}{ Remark } \\
\hline Computer & \multicolumn{2}{c}{ Minimal specification: } \\
& 1. & Processor Intel Core 2 Duo P7550 2.26 \\
& \multicolumn{1}{c}{ GHz } \\
& 2. & Memory 2 GB RAM \\
& 3. & GE Force 9400M \\
4. & Hard Disk 250 GB \\
Mobile Device & Minimal specification: \\
& 1. & Operating System Android 2.2.1 (Froyo) \\
& 2. & Processor ARMv6 600MHz \\
& 3. & Memory 279 MB RAM \\
& 4. & QVGA (240 X 320) pixel resolution display \\
& 5. & General HSDPA 7.2Mbps, 900/2100 \\
& \multicolumn{3}{c}{ MHz, EDGE/GPRS 850/900/1800/1900 } \\
& 6. & Camera \\
Database Server & https://developer.vuforia.com/qdevnet/projects \\
USB cable & A cable to connect devices to the computer. \\
\hline
\end{tabular}

Table 2. Software Requirement

\begin{tabular}{ll}
\hline \multicolumn{1}{c}{ Software } & \multicolumn{1}{c}{ Remark } \\
\hline Windows 7 & Operation system \\
QCAR SDK VUFORIA & $\begin{array}{l}\text { Java programming library } \\
\text { Software to develop program } \\
\text { Eclipse Helios }\end{array}$ \\
$\begin{array}{l}\text { with multi-language } \\
\text { programming environment } \\
\text { Android SDK (Software } \\
\text { Aevelopment Kit) }\end{array}$ & $\begin{array}{l}\text { C++ language compiler } \\
\text { CYGWIN }\end{array}$ \\
Adobe Photoshop & $\begin{array}{l}\text { Software to create and edit an } \\
\text { image }\end{array}$ \\
\hline
\end{tabular}

\section{UNIFIED MODELING LANGUAGE (UML) MODELING OF THE FRUITGARDEN}

This section will be divided into two parts. First part will explain how the process of the application through the modeling. The second part will describe the mock-up design of the FruitGarden interface.

\subsection{UML Modeling}

It has become an obsolete or an old method of development when designing an application with abstract analysis and design. Using UML tools will help developers in designing the development of an application that supports object-based programming. UML is used to build effective mobile cloud applications. The Amazon Web Service and Android mobile platform are used to model profiles and diagrams against mobile cloud-based applications. UML is used to shorten the gap between software design and implementation. UML can be used to reduce the complexity of mobile application development [8]. In this research, we modeled use case diagram, sequence diagram, and activity diagram for the application.

In the FruitGarden application, Augmented Reality user menu and the server must be connected to the image so the marker detection can be run well. Users and servers can connect when there is an internet connection or online because all data in FruitGarden recognition application stored on a server. The data will be an Augmented Reality which will automatically appear if the camera has correctly detected a marker. This FruitGarden application can also run offline, but only to see other information such as the Fruit menu that contains information and gallery of the fruits, as well as information menu. Fruit Garden application use case diagram is shown in Figure 2.

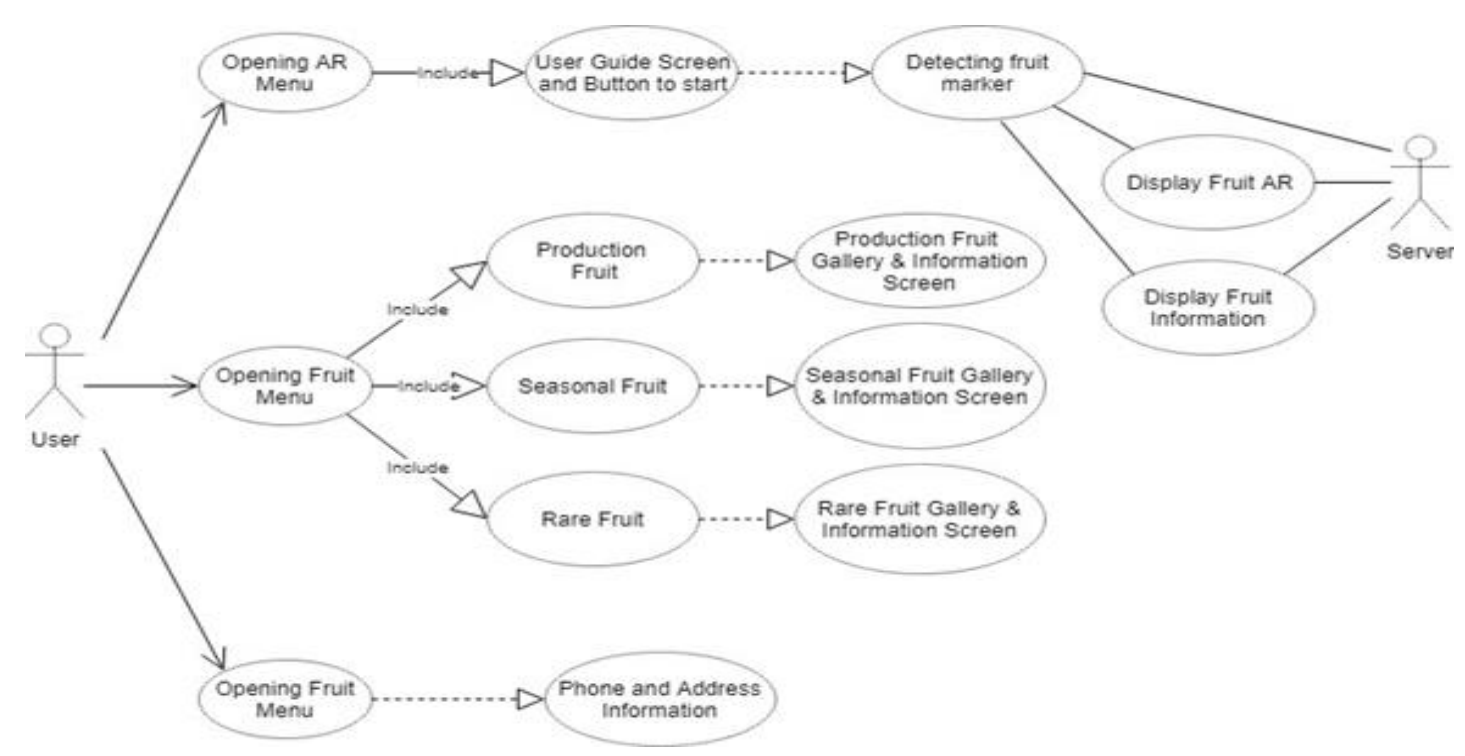

Figure 2. FruitGarden use case diagram 
Activity diagram of the FruitGarden application illustrated in Figure 3 starts with opening the main menu. There are three activity menus choice, AR menu, fruit recognition, and information. In AR menu, activity will continue to display how to use the application and a button to start detecting a marker. Fruit recognition menu consists of marker detection activity. The fruit data or information in the AR form will be shown if the application can detect marker properly. It means if we touch Augmented Reality, the fruit information will appear. In the Fruit menu activity, there are several choices of fruit collections. Each of which has different information and galleries. While the information activity will display information in the form of address and phone number of Agricultural Ministry.

Figure 4 is a behavioral representation arranged as a series of practical steps. The sequence diagram uses one actor, four participants with the lifeline bar, and nine interconnected messages. The flow begins when a user opens the application using an Android phone that will appear the main view of this FruitGarden program, which contains profile and menu. The user can select menu from the profile menu available. The menus on the profile page consist of Augmented Reality (AR), Fruit (fruit gallery), and info (address and phone number).

The first application will go into the main page view, but the internet network relates to the mobile Android must be available. On the main page, profile selects the Augmented Reality (AR) menu, after the entry will immediately appear the procedure of using the AR application. This page has a button menu to start Recognition marker. Recognition marker requires several processes for the detection by the Vuforia server. If the marker detection process is successful then Augmented Reality FruitGarden will appear along with additional information. Other menus can also be selected in use of this application, another menu consisting of Fruit (fruit gallery) and info (information). The fruit menu contains a gallery of fruit and info menu containing address information and phone number of Agricultural Ministry.

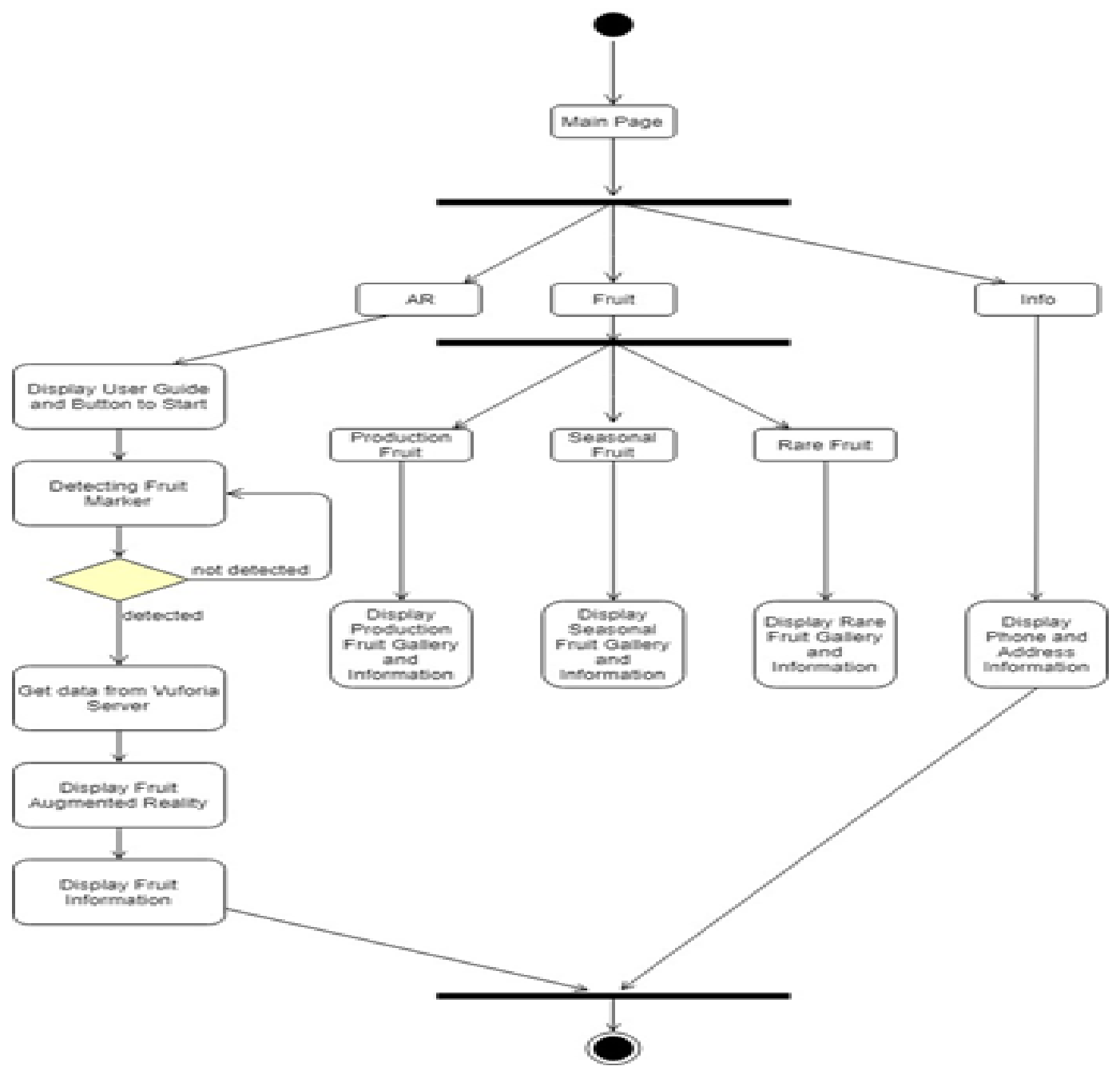

Figure 3. FruitGarden activity diagram 


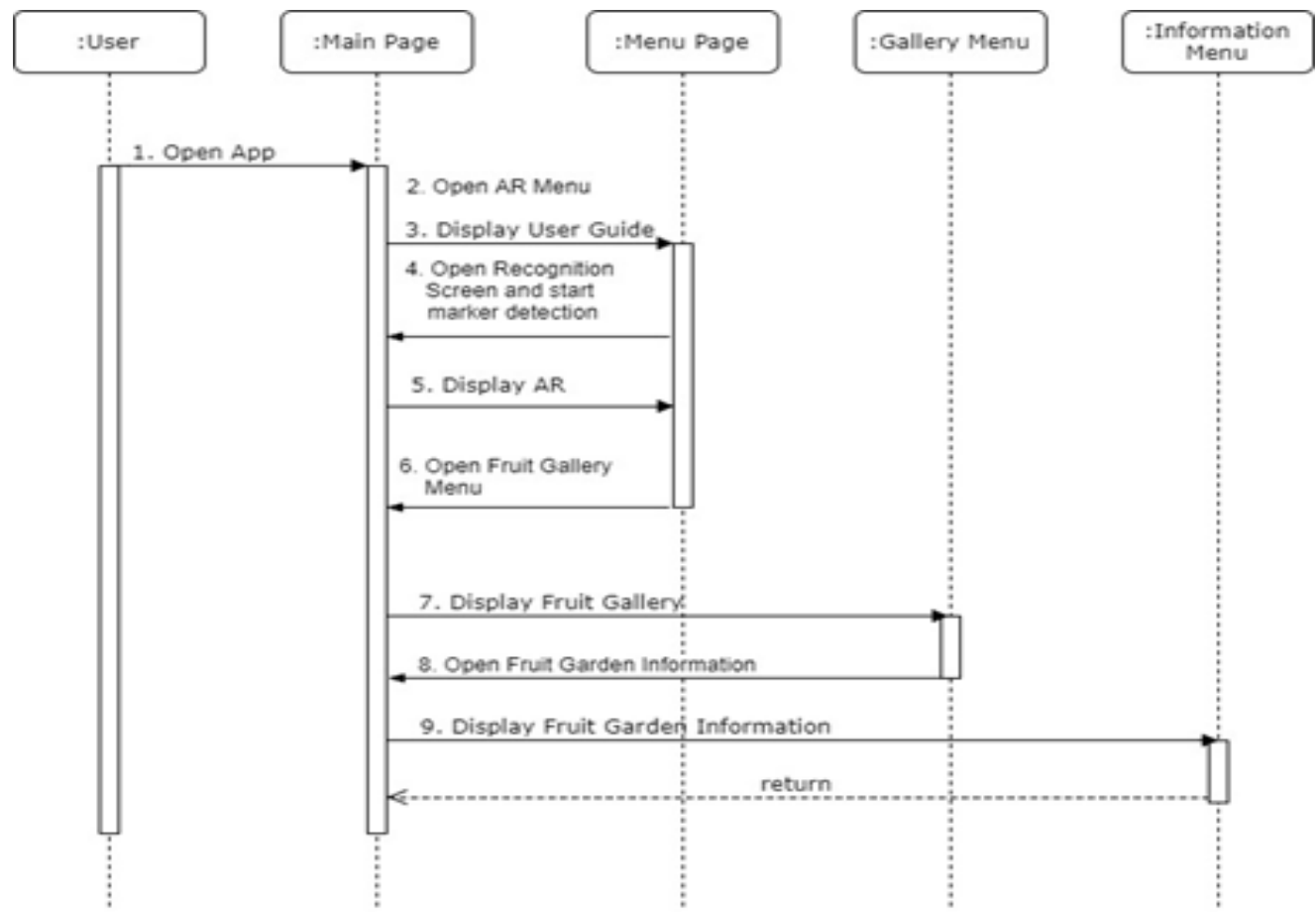

Figure 4. FruitGarden sequence diagram

\subsection{Interface Design}

This section will explain the interface designs will be built in this FruitGarden application. Broadly designed Interfaces to be explained divided into two, the main page design and the design of the menu page. The design of the main page of this application is a splash screen and profile. The main page has several menus, Augmented Reality (AR) menus, Fruit (fruit gallery), and Information.

The interface design in this section contains a splash screen and profile. On the main page, the splash screen will first appear on the opening page. While the main page profile as the parent page in this application, shown in Figure 5. The splash screen on the top page contains the opening image that appears a few seconds before the profile page. After the splash screen appears then the next is to display the main page profile application which contains the menu button and text as in Figure 6.

The interface design on the AR menu page contains information on how to use AR Recognition. The page informs the steps user must perform before using the application. When the user has grasped the stages then the user can immediately start the Recognition marker to get Augmented Reality. The design of the page can be seen in Figure 7.

Once the user starts the Recognition marker then the Augmented Reality view will appear. On this AR page, the user can also see the about and profile menu. This menu contains flash on (activate camera flash), cont. Autofocus for a camera and then about the application developer. The design of the page can be seen in Figure 8.

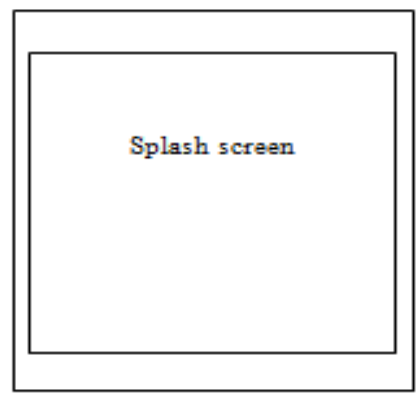

Figure 5. FruitGarden splash screen home page 


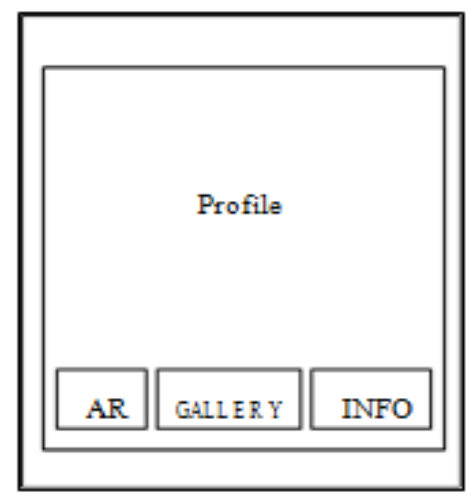

Figure 6. FruitGarden profile in main menu

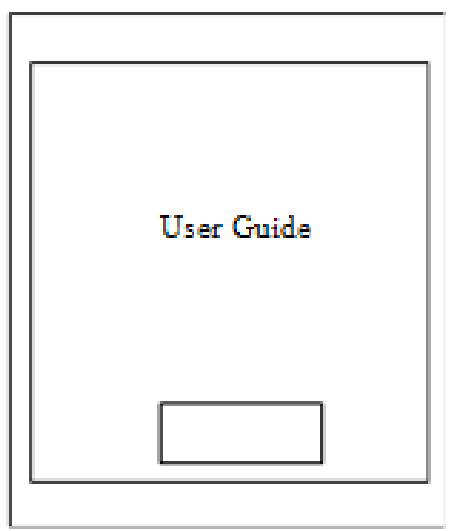

Figure 7. FruitGarden AR menu page

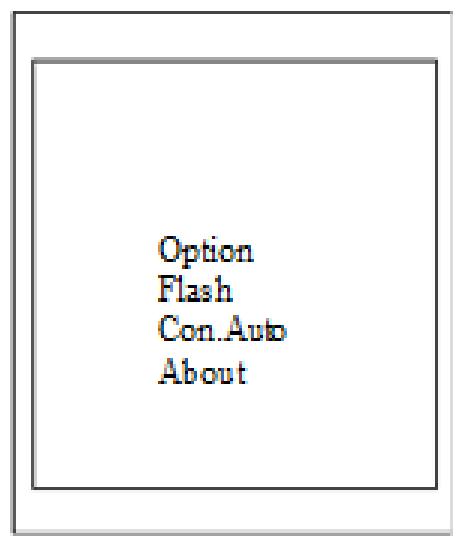

Figure 8. FruitGarden alert menu option

The interface on the Fruit menu page contains a gallery of fruits. This fruit gallery is an additional feature in the FruitGarden application. With this additional feature, users can view the fruit list available for Augmented Reality. Hence, the user has no difficulty in getting the information. The design of the fruit page can be seen in Figure 9.

The FruitGarden page in Figure 9 consists of several fruit menus, rare fruit, production fruit and seasonal fruit. The fruit is original Indonesian fruits. Inside the menus contain fruit information and gallery menu. In the Gallery menu on the information page contains pictures of the fruit, the fruit is a common object fruit for tourism. Figure 10 shows the fruit gallery. Figure 11 shows information page. 


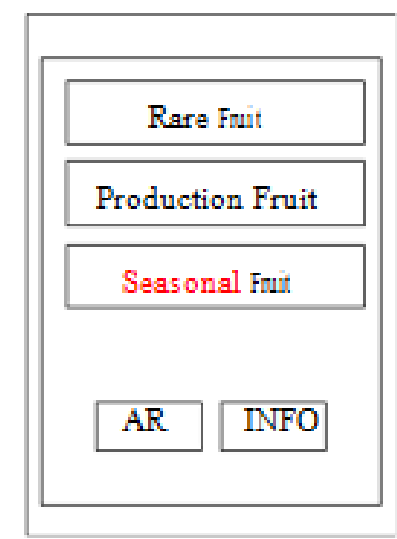

Figure 9. FruitGarden menu page

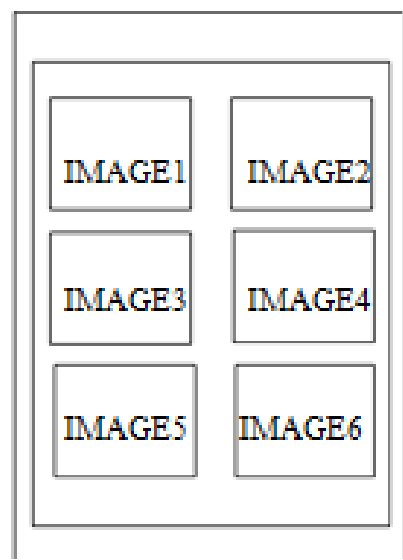

Figure 10. Fruit image on FruitGarden gallery page

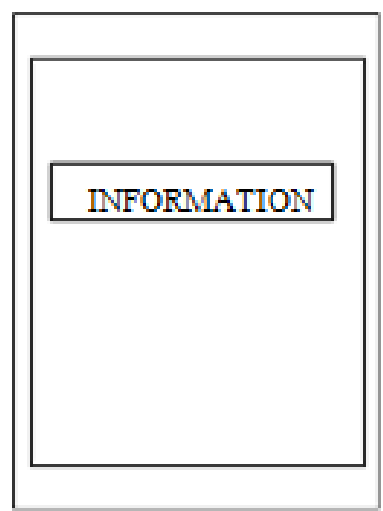

Figure 11. FruitGarden information page

Making Augmented Reality requires a camera that is feasible for the marker recognition process for the application to run properly. As well as a good program design can recognize the marker quickly [9]. Then we do start the marker project and ensure that all the required tools are installed properly. In addition, metadata is a data file should be made that contains the name JSON. The file will be uploaded into FruitGarden database on Vuforia [10]. Metadata is created using notepad and then fill with the same JSON 
names as the JSON files on the content. Making FruitGarden Augmented Reality requires some images of fruits as the image uploaded to the server Vuforia and used as a marker [11]. The site of https://developer.vuforia.com/ will be used to upload these fruit images. Before the image is uploaded, the first image is processed digitally by using Paint and Photoshop to have better quality. This fruit images will have emerged in three-dimensional form.

This AR application can be expected combined with other agricultural fields research. A research of image processing diagnoses the leaves disease is possible to be embedded into AR [12]. Evaluation of the condition of the fruit has experimented. However, there are several techniques performed in the agricultural industry, especially in observing the conditions in the fruit. Quality of fruit and maturity level is the evaluated parameters. Smooth evaluation techniques are using ultrasonic measurements, light spectroscopy, MRI and $\mathrm{X}$-Ray, computer vision, and others. Evaluation of using AR technique is also challenging [13].

\section{CONCLUSION}

An Augmented Reality design application, the FruitGarden will recognize fruit types of using cloud recognition method on the Android mobile device. This application will display the information of the existing fruit by using the camera on handphone so that user can easier to know the information of the fruit in real-time, interesting and interactive details. This proposed method is different in any fruit recognition system available. The implementation will be worked later. This FruitGarden application enriches the AR technology in objects variation.

\section{ACKNOWLEDGEMENTS}

This work is partially supported by Indonesia Ministry of Research Technology and Higher Education-Kemenristekdikti Grant No. 0421/K3/KM/2017.

\section{REFERENCES}

[1] Chee Oh Chung, Yilun He, Hoe Kyung Jung, “Augmented Reality Navigation System on Android”, International Journal of Electrical and Computer Engineering (IJECE), Vol. 6, No. 1, pp. 406-412, February 2016.

[2] Folorunso Olufemi A., Mohd Shahrizal S., Ikotun Abiodun M., "Augmented Reality Prototype for Visualising Large Sensors' Datasets", TELKOMNIKA (Telecommunication, Computing, Electronic and Control), Vol.9, No.1, pp. 161-170, April 2011.

[3] Seng, Woo Chaw, and Mirisaee, S.H., “A New Method for Fruits Recognition System”, ICEEI'09 International Conference on Electrical Engineering and Informatics, Vol. 01, pp.130 - 134, 2009.

[4] Jana, Susovan, Parekh, Ranjan, "Intra-class Recognition of Fruits using Color and Texture Features with Neural Classifiers", International Journal of Computer Applications, Vol. 148, No.11, 6p, August 2016.

[5] Cheng, Hong, Damerow, Lutz, Sun, Yurui, Blanke, Michael, "Early Yield Prediction Using Image Analysis of Apple Fruit and Tree Canopy Features with Neural Networks", Journal of Imaging, Vol. 3, No. 6, 13p, 2017.

[6] Dewi Agushinta R., Ihsan Jatnika, Henny Medyawati, Hustinawaty, "A Method of Cloud and Image-Based Tracking for Indonesia Fruit Recognition”, International Conference on Engineering, Technologies and Social Sciences 2017, 5p, 7-8 August 2017.

[7] Booch, Grady, Rumbaugh, James, Jacobson, Ivar, Unified Modeling Language User Guide, 2nd Edition, AddisonWesley Professional, 2005.

[8] Dong Kwan Kim, "Development of Mobile Cloud Applications using UML", International Journal of Electrical and Computer Engineering (IJECE), Vol. 8, No. 1, pp. 596-604, February 2018.

[9] Kim, Young-Geun and Kim, Won-Jung "Implementation of Augmented Reality System for Smartphone Advertisements", International Journal of Multimedia and Ubiquitous Engineering, Vol.9, No.2, pp.385-392, 2014.

[10] Irma Permata Sari, Selo Sulistyo, Bimo Sunarfri Hantono, 2014, "Evaluasi Kemampuan Sistem Pendeteksian Objek Augmented Reality secara Cloud Recognition", Seminar Nasional Aplikasi Teknologi Informasi (SNATI), Yogyakarta, H-1-6, 21 Juni 2014.

[11] Lee, Youngho, and Choi, Jongmyung Assigning 3D Content to User Defined Targets for eBook reader with Augmented Reality Technology, Advanced Science and Technology Letters, Vol.42 (Mobile and Wireless 2013), 2013, pp.69-72.

[12] S. A. Dhole, Rukaiyya P. Shaikh, "Review of Leaf Unhealthy Region Detection Using Image Processing Techniques", Bulletin of Electrical Engineering and Informatics (BEEI), Vol. 5, No. 4, pp. 466-468, December 2016.

[13] Mohd Fadzli Abd Shaib, Ruzairi Abdul Rahim, S. Z. M. Muji, Azian Abd Aziz Ahmad, "Investigating Maturity State and Internal Properties of Fruits Using Non-Destructive Techniques-A Review", TELKOMNIKA (Telecommunication, Computing, Electronic and Control), Vol.15, No.4, pp. 1574-1584, December 2017. 


\section{BIOGRAPHIES OF AUTHORS}

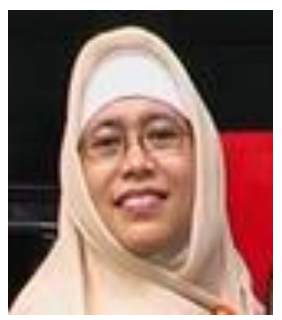

Dewi Agushinta R. had her Bachelor degree in 1993 and Doctoral degree from Gunadarma University in 2007. Her Master degree was from Asian Institute Technology at Bangkok, Thailand. She is giving some lectures in the Department of Information System at Faculty of Computer Science and Information Technology. Her interest research is in Human-Computer Interaction, Image Processing, and Information Technology.

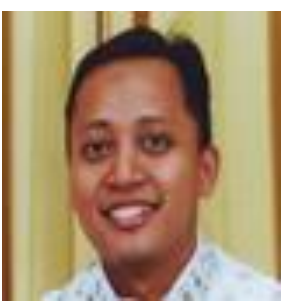

Ihsan Jatnika had his Bachelor and Master degree from Gunadarma University. His field is on informatics. He is a Doctoral student at Gunadarma University. His subject teaching is Knowledge-Based System, Computer Architecture, and Organization. He is experts on the programming.

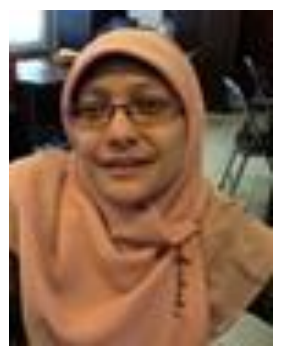

Henny Medyawati pursued her Bachelor, Master, and Doctoral degree from Gunadarma University. She took Master and Doctoral degree in management field. She is also interested in computer science field. Her research interest is Information System, Banking System, and Economy as well.

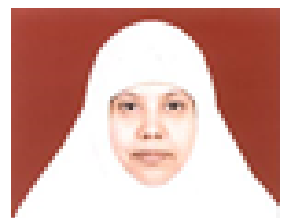

Hustinawati is a programming expert. She does the programming. She teaches programming until now. Her Bachelor, Master and Doctoral degree got from Gunadarma University. Her subject teaching is web-based programming system. Now she is one of the laboratory head in Lembaga Pengembangan Komputer (LePKom). 